\title{
Funding open access monographs A coalition of libraries and publishers
}

$\mathbf{S}$ cholarly monographs present one aspect of open access (OA) publishing that is just beginning to see the sustained analysis that comes with reliable data. Until recently, actual hard data on the publishing costs and revenue associated with academic books was conspicuously absent from the debate over OA. Studies such as the ones undertaken by Ithaka ${\mathrm{S} \& \mathrm{R}^{1}}^{1}$ and OAPEN-NL ${ }^{2}$ are addressing this gap, giving us for the first time the means to assess the costs of, and revenue streams for, OA monographs in relation to the "legacy" publishing model.

Here we consider the OA business model employed by our company, Open Book Publishers (OBP), ${ }^{3}$ based in the United Kingdom. We first outline how publication of OA monographs redresses problems of reach and dissemination inherent to traditional publishing practices for academic books. We summarize other key OA business models currently employed in the United States and United Kingdom and demonstrate how, with a combination of cost-efficient production, revenue from sales, the targeted use of publishing grants, and library coalition support, OBP has developed a sustainable publishing model to:

1. publish only high-quality research;

2. maximize readership of the content of the works published;

3. maximize engagement with, and re-use, of the works; and

4. improve the quality, range, and scope of academic research by encouraging and developing innovative outputs.
Using our own costs, sales, and readership data, we also make the case that social enterprises are an appropriate mechanism for delivering the opportunities OA provides.

\section{The problem of the legacy publishing} model: Good business, bad dissemination By legacy model, we refer to the practice of commercial publishers and many university presses to produce printed volumes, typically priced from $\$ 80$ to $\$ 100$, for which lifetime sales are often estimated to be from 200 to 400 copies-sold primarily to university libraries. This model is coming under mounting pressure. Mandates for OA by research funders, declining sales of monographs, and the increasing need of those within the humanities and social sciences (HSS) to justify their disciplines by way of their public impact make a potent case for changing the publishing landscape.

Despite such pressure, the legacy model remains remarkably resilient. While noting a dramatic fall-off in sales of monographs, Geoffrey Crossick observed in his recent report that the number of research monographs published globally appears to have grown. ${ }^{4}$ Monograph publishing by the "big

Rupert Gatti is director, email: rupert.gatti@ openbookpublishers.com, and Marc Mierowsky is editor of Open Book Publishers, email: marc@ openbookpublishers.com

O 2016 Rupert Gatti and Marc Mierowsky, Creative Commons Attribution 4.0 (CC BY 4.0 - https://creativecommons.org/licenses/by/4.0/) 
four" U.K. academic monograph publishers has nearly doubled over the last ten years. ${ }^{5}$ It is probably fair to say that, despite the fall in actual sales, the legacy publishing model remains successful as a business model, at least insofar as the profits of publishers are concerned.

Yet, sales of 200 to 400 titles mean that effectively nobody is reading the work, so as a model of dissemination it is failing. The consequences of this failure are alarming. Increasingly, funding authorities are questioning the role and impact of research in HSS disciplines. Funding for HSS is often a "poor cousin" to STEM.

Japan's government, for example, recently encouraged universities to close their HSS faculties altogether-with 26 of 60 national universities now planning to close or convert HSS faculties to "areas that better meet society's needs." ${ }^{\prime 6}$ These developments present a catch-22 for OA monographs. With decreasing funding there is often not enough money to cover the fees demanded by many OA publishers of their authors.

According to the Ithaka S\&R report, the average cost of producing a digital monograph exceeds $\$ 30,000$, but can range from as low as $\$ 16,000$ to more than $\$ 100,000$. Not all studies have obtained such high figures. The OAPEN-NL study shows the average "first copy" cost of producing OA monographs in the Netherlands to be $€ 7,800$ $(\$ 10,600))^{7}$ This, and our own experience, suggests that much more cost-efficient publishing processes are possible-but clearly monograph publishing costs still do need to be covered. The question, for publishers and, indeed, for the whole scholarly community, is how to offset these costs.

\section{Additional business models: Publishing charges and library coalitions}

The primary source for OA funding among legacy publishers is a direct publishing charge to the author, or the author's funding body. Publishing charges vary considerably: Brill charges $\$ 6,675$ for a CC BY-NC licensed monograph —rising to $\$ 18,500$ for CC BY- and Palgrave Open charges $\$ 17,000$ for CC BY. ${ }^{8}$ Many funding bodies and universities will find publishing charges of these levels difficult to finance. These fees may reinforce entrenched privileges, giving only those scholars with generous institutional backing the capacity to publish OA monographs.

The development of library coalitions provides an exciting alternative model, with the potential to harness the strengths of libraries to create an efficient, flexible, and dynamic OA publication and dissemination infrastructure. Different examples of this approach have emerged, in some cases creating new publishing operations, such as the Lever Press, funded by a consortium of U.S. liberal arts colleges, and White Rose University Press, funded by a regional coalition of universities in the United Kingdom. In other models, library coalitions are partly funding the OA publishing operations of existing publishers (e.g., the Luminos program under the University of California Press) or directly offsetting charges for the OA publication of specific titles (e.g., Knowledge Unlatched). But there remains the potential for library coalitions to take a direct and active role in creating and supporting networks for the effective dissemination, discovery, and archiving of OA titles that we have not seen developed for monographs.

\section{OBP's integrated approach: Costs and revenue}

OBP offers a cost-efficient alternative to the predominant business models. As a registered nonprofit, our financial business model is to break even. This is important, as without hungry shareholders to satisfy with increasing profit margins our objectives can remain focused solely on effective publication and dissemination of research, which we are able to demonstrate to all stakeholders involved (authors, referees, libraries, etc.).

At OBP we have adopted a traditional peer-review process. We subject all accepted titles to rigorous copyediting and provide targeted marketing for each of our published 
titles. Along with a free HTML edition and PDF reader at the OBP website, we also offer five retailed editions (hardback, paperback, EPUB, MOBI, and an enhanced PDF). Our costs are, however, far lower than those of other publishers.

- Distribution figures: Free editions of our titles are made available from many different platforms-including Google Booksmany of which we are unable to monitor. However, for those we can monitor, we have found that each of our titles receives an average of 400 online readers per month, totalling an average of 5,000 readers per annum-a staggering number considering that most traditionally published academic books max out at around 400 sales over their entire lifetimes. In addition, readers are accessing our titles from nearly every country on earth. ${ }^{9}$

- Cost figures: Figures from our last financial accounting year (ending September $30,2015)^{10}$ show that our total costs for the year were $£ 108 \mathrm{k}(\$ 163 \mathrm{k}) .{ }^{11}$ We benefit from rent-free office space, so for fair comparison with other publishers we should add a cost of around $£ 12 \mathrm{k}$ ( $\$ 18 \mathrm{k}$ ) for this, bringing our total costs over the period to $\$ 120 \mathrm{k}$ ( $\$ 180 \mathrm{k}$ ). But this figure includes post-publication print and distribution charges of $£ 20 \mathrm{k}$ ( $\$ 30 \mathrm{k}$ ), so for comparison with the "first copy" costs in the Ithaka S\&R study, we subtract these and use a figure of $£ 100 \mathrm{k}$ ( $\$ 150 \mathrm{k})$ —which includes all nonsales costs. In this same period we published 18 new titles. A simple division of overall costs by the number of books gives an average cost of $£ 5,555$ $(\$ 8,333)$ per title-a figure significantly lower than those reported by Ithaka $S \& R$, suggesting that substantial cost reductions may be feasible at those presses.

- Revenue figures: Our revenue for the period was £111k (\$168k), exceeding our costs by $23 \mathrm{k}(\$ 4.5 \mathrm{k})$ — which for a nonprofit is the definition of success. Revenue is drawn from three main sources:

1. Sales: $£ 45 \mathrm{k}$ ( $\$ 68 \mathrm{k}), 41 \%$ of total revenue. Paperback sales account for about two-thirds of this figure.
2. Publishing grants: Also $£ 45 \mathrm{k}(\$ 68 \mathrm{k})$, $41 \%$ of total revenue. At OBP we do not charge authors or their funding bodies for publication. We do, however, encourage authors to apply for any available grants, although publication is never made contingent on their success. The majority of these grants are not targeted specifically for OA publications.

3. Library membership fees: $20 \mathrm{k}$ (\$30k), $18 \%$ of total revenue. For a fee of $£ 300$ ( $\$ 500$ or $€ 400$ ), participating libraries have a range of benefits, including free access for all university members to the full range of formatted digital editions of all of OBP's books, usage statistics, and the ability to upload any of our titles' digital editions to their own online repository or e-book collection to keep, search, archive, and share permanently. Thanks to one library member, St. Andrews University Library, ${ }^{12}$ we are also able to supply all libraries with a complete set of MARC records for all our titles. As such, OBP capitalizes on the strengths of libraries in collection, dissemination, discovery, and archiving, as well as in funding.

We are pleased we can break even without having to impose publishing charges on authors. Clearly, sales revenue alone is not sufficient to cover our costs, and the existence of publishing grants and the financial support received from library membership has been absolutely critical for our financial viability.

\section{A new way forward}

The increasing demand for monographs to be made OA has the potential to reshape the way research in HSS is disseminated. But the "legacy" business model, based exclusively around sales revenue, seems unlikely to be feasible for OA publications. Commercial publishers have little alternative to charging high OA publication fees to authors or their institutions.

What OBP demonstrates is that social enterprises and nonprofits can play a leading role in the drive to make research openly accessible. We have shown that it is, indeed, 
possible to reduce the production and distribution costs significantly for academic monographs from the levels adopted by legacy publishers, and to enable OA monograph publishing at no cost to authors. By embracing digital and OA technologies, our experience demonstrates that there are substantial cost efficiencies achievable in academic monograph publishing.

The direct financial support provided by research funders, scholarly societies, and libraries for OA publishing through publication grants, membership fees, and other nonsales revenue sources is likely to be even more important for new publishing initiatives than for legacy publishers (which are typically able to sustain sales revenue via established purchasing plans with libraries).

These new initiatives bring innovation and dynamism to the whole scholarly dissemination landscape and should be encouraged by libraries, which-by acting collaboratively_can become leaders within the scholarly publishing ecosystem rather than mere product purchasers. Recognizing this and ensuring that any alternative funding sources developed for OA publications are made easily accessible by new publishing initiatives, and not effectively restricted to the established publishers, are of paramount importance if we wish to create an innovative and dynamic OA, academic publishing environment.

\section{Notes}

1. Nancy L. Maron et al., "The Costs of Publishing Monographs: Toward a Transparent Methodology," Ithaka S+R, last modified February 5, 2016, http://dx.doi.org/10.18665 /sr.276785.

2. Eelco Ferwerda et al., "OAPEN-NL: A project exploring Open Access monograph publishing in the Netherlands," 2013, https://core.ac.uk/display/30675760.

3. Visit www.openbookpublishers.com/.

4. Geoffrey Crossick, "Monographs and Open Access Project," January 2015, www. hefce.ac.uk/pubs/rereports/year/2015 /monographs/.

\section{Ibid.}

6. "Japanese government asks universities to close social sciences and humanities faculties," ICEF Monitor, September 17, 2015 , http://monitor.icef.com/2015/09/japanese -government-asks-universities-to-close -social-sciences-and-humanities-faculties/.

7. Figures taken from Maron et al., Table 1 , and Ferwerda et al., Table 4 (excluding costs for printing and distribution).

8. See http://www.brill.com/about/open -access/publication-charges, www. nature.com/openresearch/publishing-with -palgrave-macmillan/publication-charges/.

9. Readership and geographic data for our titles is available on each of the bookpages on our website at www.openbookpublishers. $\mathrm{com} /$.

10. OBP Annual Accounts are publicly available at https://beta.companieshouse. gov.uk/company/06707027/filing-history.

11. Using US/GBP exchange rate on October 1, 2015, of 1.5132, present (postBrexit) exchange rates would make the U.S. figures more than 10\% lower.

12. Janet Aucock and Elizabeth Cuthill "Cataloguing partnership" Catalogue E Index, 181 (2015), 20-26, www.cilip.org.uk/sites /default/files/documents/catalogue_and _index_issue_181_december_2015.pdf. $\boldsymbol{n}$

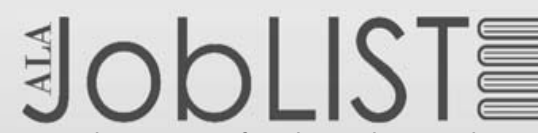 \\ The \#1 source for jobs in Library and Information Science and Technology \\ JOB SEEKERS \\ Search and sort hundreds of job ads by position type, employer, location, and more}

\section{EMPLOYERS}

Strengthen your candidate pool-

ALA reaches the most engaged professionals and students
ALA HRDR ACRL

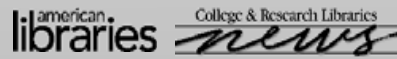 joblist.ala.org 